\title{
The Vector Model of Competence Diagnostics
}

\author{
Andrei Viktorovich Dorofeev ${ }^{1}$ \\ Al'fiia Faizrakhmanovna Latypova² \\ ${ }^{1}$ The Department of Mathematical Analysis, Sterlitamak Branch of the Bashkir State University, Sterlitamak, Russian Federation \\ ${ }^{2}$ The Department of Natural Sciences and General Professional Disciplines, Ufa State Aviation Technical University, \\ Sterlitamak Branch, Sterlitamak, Russian Federation \\ Email: an-dor2010@yandex.ru
}

\section{Doi:10.5901/mjss.2015.v6n4s4p11}

\section{Abstract}

The article summarizes the results of the theoretical study of the problem of diagnostics designing that takes into account the multidimensional nature of competence. Competences aggregate inconsistent components. Therefore, in order to describe them, it is natural to apply the category of multidimensionality. The essence of the multidimensionality concept is explained in the context of the competence-centered education. Multidimensionality is the most adequate and volumetric characteristic of the described reality. Education is understood as a process of competences formation. Pedagogical diagnostics is an integral part of the learning process. The multidimensional nature of competences necessitates the development of appropriate methods and means for their diagnostics. The article clarifies the role of diagnostics as the means of education activity management. The content of the diagnostic activity is disclosed according to its three interrelated directions: control, correction, and forecasting. The following principles of pedagogical diagnostics are defined: multidimensionality, continuity, anthropocentrism, and objectivity. The diagnostic functions are specified for each of its directions. The construction of the diagnostic instruments is based on the theoretical model of diagnostics. The choice of the multidimensional vectors is substantiated for building a model of pedagogical diagnostics. The competence elements' formalization is carried out in the form of component parts of the multidimensional vectors. It is shown that the use of operations on vectors allows reflecting the dynamics of the formation of competences. The individual educational path designing is implemented by means of the vector model.

Keywords: vector modeling, multidimensionality, competences, pedagogical diagnostics, individual educational path

\section{Introduction}

The modern education is designed within the competence-building approach that involves not only education and upbringing, but also self-education and self-improvement. Indeed, within the information society, the generations of technologies interchange faster than generations of people. A contemporary person must be able to act in a constantly changing environment. A person's successful self-fulfillment in the personal, social, and professional fields is determined by the availability of skills in planning, analyzing, and correcting the activity, and developing an individual strategy for each new situation. The foundation of these skills is the capacity for self-education and readiness for self-development. Therefore, the main objective of the modern education is a personality that, first of all, possesses the competences of self-cognitive and self-development activity; capable of setting goals and achieving them based on the educational competences.

The focus of education is shifted towards the formation of the abilities for self-fulfillment. The desire to bring the learning process closer to life, to increase the efficiency of the education results is reflected in the fact that the content and arrangement of the learning process focus on competences. The cognitive, as well as operational and technological, components of the competence-related education results are integrated with the system of ethical, value-related, and motivational orientations of a student. As the generalized modes of actions, the competences are intended to ensure the productive performance of the cognitive learning and socio-professional activities by the students. The formation of competences requires the system of higher education to implement brand new education not by increasing the academic training, but through focusing the academic discipline on the development of the student's abilities for creative search and continuous replenishment of knowledge. The theoretical justification of the education result's multidimensionality generates a need for developing the technological support of the competences formation.

The issues related to the investigation of multidimensionality are considered in the works written by Bogataia L.N., Morgun V.F., Steinberg V.E., and Ialalov F.G. The aspects of the diagnostic activity, as an integral part of the educational 
process, under the new conditions are examined by Almazova O.V., Dmoshinskaia N.G., Mikhailychev E.A., Ushakov A.A. et al. The contemporary pedagogical researches cannot be imagined without the use of various types of models. The works written by lasvin V.A., ladrovskaia M.V., Kiseleva O.M., Timofeeva N.M., and Bykov A.A. are devoted to the study of modeling in pedagogics.

The result of the vocational education drawn up in the terms of competences is multidimensional. Therefore, the formation and diagnostics of the competences should be based on the principle of multidimensionality (Dorofeev and Latypova, 2015). Due to the fact that the competence aggregates characteristics of different nature, it is necessary to develop the diagnostic techniques that will be adequate to the object of study.

The following problem is actualized: What should be the model of diagnosis that takes into account the multidimensional nature of competence and reflects the dynamics of its formation process?

The directions of the search for the diagnostic model are determined by the peculiarities of the diagnostic activity in the conditions of a competence-centered education. These features are reflected in the diagnostic principles we have set up earlier. This paper highlights the following directions of the diagnostic activity: control, correction, and forecasting. The diagnostic functions are specified for each of these directions. The principles provide the basis for the provisions determining the choice of the multi-dimensional vectors as a mathematical model of the competence diagnostics.

In the modern conditions, the arrangement of education as a social institution, as indicated by the philosopher R.A. Nurullin, requires a harmonious combination of the vertical and horizontal control. Therefore, professional education requires a shift towards the self-tracing educational technologies and self-education systems (Nurullin, 2013). In this regard, we consider it significant to use the vector method for designing an individual educational path.

\section{Literature Review}

\subsection{Multidimensionality as a pedagogical category}

The problem of space multidimensionality is covered by mathematics, but the methodological aspects of multidimensionality are also addressed by other sciences. In philosophy and psychology, multidimensionality is more often associated with the methodological problems of cognition (Bogataia, 2012; Morgun, 1992). The category of multidimensionality is used to characterize the life experience of a person, which integrates the "thought-out," the "heartfelt," and the "fulfilled" (Anan'ev, 1968). Indeed, it is necessary to rely on the multidimensional life experience of a student, so that he could be an equal participant of the learning process and become the subject of the knowledge discovery and use.

The idea of multidimensionality is also reflected in pedagogical research. The theoretical provisions for building didactic multidimensional instruments in order to present knowledge in the natural language were developed by V.E. Stejnberg. According to him, the instrumental basis of the traditional and perspective learning technologies must meet the requirements of the universality, multidimensionality, and genetics (Stejnberg, 2001).

As indicated by V.E. Stejnberg, the knowledge representation in the form of multidimensional and semantic spaces corresponds to the peculiarities of the stage of verbal cognitive activity, and is one of the few universal ways of knowledge representation. This allows us to consider multidimensionality as a didactic category that enriches the science with a new concept-the didactic multidimensional instruments (Stejnberg, 2002).

Addressing the category of "multidimensionality" in the philosophical, psychological, and pedagogical studies demonstrates the need for a more adequate and volumetric characteristic of the reflected reality. Multidimensionality has the primal and more concise meaning with regard to the closely related notions of multidirectionality, multilevelness, and multifacetedness. Multidirectionality demonstrates the property of "separation," and multidimensionality—of the complementary synthesis of parts, that provides the system with a new quality. Allocating the set of characteristics allows measuring the condition, change, and development of the system. Multilevelness and multifacetedness are closely related to the categories of "segmentation" and "allocation" of certain levels (faces) within the system. The level-based division involves the system classification by any attribute, which is also not the same as multidimensionality.

Addressing the category of "multidimensionality" in humanitarian studies is a way to integrate the individual units within a similar system creating unified directionality of any quality or value. Thus, multidimensionality as a pedagogical category is especially significant for the analysis and design of the competence-centered vocational education.

\subsection{Multidimensionality in vocational education}

First of all, the multidimensional nature of a person is manifested in his professional activity. 
Professional multidimensionality is the world of multidimensional competences that have an integrative framework. Ialalov F.G. puts across the meaning of "multidimensional competences" as the integrative, applied skills and abilities that provide for the multidimensionality of a specialist in any sphere of activities (Ialalov, 2012).

Professional multidimensionality serves as a special form of creative self-development of a specialist and as a versatile technology for labor intensification. Ialalov F.G. identifies four main integrative multidimensional competences: mobility (the ability to orient oneself in three worlds: internal, external, and virtual); synergy (the ability for selforganization); multitasking (the ability to solve several independent problems while performing one task); and versatility (the ability to simultaneously perform multiple duties at a sufficiently high level). The formation of the multidimensional professional competences suggests that one should have structured memory, multivectoral attention, and integrative and flexible thinking (lalalov, 2013).

The multidimensionality of a person manifests itself as an indissoluble unity of the biological and the social, the physical and the spiritual as well as the typical and the individual. All the marked items are interrelated and interdependent (Sabirov, 2012). Therefore, a multidimensional personality is self-sufficient and capable of selfdevelopment.

The performed analysis allows concluding that the essential characteristic of the competence-building approach in education manifests itself through the integrativity. The category of "multidimensionality" allows to commensurate relationships between the components of the educational system determining its new qualities. One of such qualities within the system of vocational training may be the focus on the formation of the student's ability for self-development and diagnostics of the personal level of professional competences development that appear for the multidimensional result of education.

\subsection{Pedagogical diagnostics as a means of the learning activity management}

In 1968, the term "pedagogical diagnostics" was suggested by the German scientist K. Ingenkamp. He defined the concept through the diagnostics direction:

- Optimization of the individual learning process.

- Proper determination of the learning outcomes.

- Minimization of errors in differentiation of students.

In achieving the above-mentioned goals, pedagogical diagnostics is applied to determine the learning outcomes and the further analysis of the educational process as a whole (Ingenkamp, 1991). Accordingly, the objects of pedagogical diagnostics are the student and the teacher as well as the content, methods, tools, and results of the pedagogical activity.

As indicated by A.A. Ushakov, pedagogical diagnostics aims to improve the educational process and focuses on the internal and external correction, confirmation of the successful learning outcomes, the planning of the learning process stages, motivation, and the adjustment of the complexity of the subsequent steps (Ushakov, 2010).

The aim of pedagogical diagnostics as a relatively independent branch of pedagogical knowledge is to deliver a pedagogical diagnosis and pedagogical correctional measures (Mikhailychev, 2004).

An analysis of the categorical field of the "pedagogical diagnostics" concept is presented in the work (Almazova, 2007). We have structured the results of the study carried out by the author in Table 1.

Table 1. The approaches to defining the concept of "Pedagogical Diagnostics"

\begin{tabular}{|l|l|l|}
\hline Form & Focus & Content \\
\hline Type of pedagogical activity & $\begin{array}{l}\text { Analytical and information support of } \\
\text { the educational and parenting } \\
\text { process }\end{array}$ & $\begin{array}{l}\text { The system of methods, techniques, and forms for collecting and interpreting the } \\
\text { data on the current state of the elements and parameters of the pedagogical } \\
\text { systems, processes, relationships, and their subjects. }\end{array}$ \\
\hline Act of cognitive activity & $\begin{array}{l}\text { Recognition of the current state of a } \\
\text { single object in its relation to the } \\
\text { standard }\end{array}$ & The psychological mechanism for collecting empirical information. \\
\hline Area of pedagogical science & $\begin{array}{l}\text { Analysis and synthesis of the } \\
\text { diagnostic processes }\end{array}$ & $\begin{array}{l}\text { The scientific discipline that studies the regularities of rendering the diagnostic } \\
\text { judgements on the elements and parameters of the pedagogical systems, } \\
\text { relationships, and their subjects, the rules of carrying out the diagnostic procedures; } \\
\text { the principles, methods, and forms of diagnostics in the field of pedagogics. }\end{array}$ \\
\hline
\end{tabular}

In the monograph (lakushevich and Burmakina, 2013), the classification of the "pedagogical diagnostics" concept is performed from the perspective of complexity of the problems to be solved. Within the context of the approach specified, 
we consider it legitimate to allocate the stages of diagnostics. At the first stage, the progress of knowledge and skills formation is recognized. The level of knowledge and abilities the student possesses at a given time is identified. The problems of interpretation are the next to be resolved-why the student's level of knowledge and skills is what it is? The content of the third stage is the pedagogical forecasting. Reasonable assumptions on what the student's level of knowledge and skills will be in the future are put forward.

Thus, the diagnostics is the theory and practice of diagnosing, which when in terms of the education sphere is considered in two meanings. On the one hand, a diagnosis indicates the causes of any ill-being with the purpose of its elimination. Such a diagnosis involves decision-making on the appropriate impact on the object being diagnosed, which leads to subsequent corrective actions. On the other hand, a diagnosis involves comprehensive, holistic examination of the object, in particular, of a specific student or the entire training group to assess their state.

Pedagogical diagnostics is an integral component of the pedagogical activity, since the implementation of the processes of education and parenting requires assessment, analysis, and consideration of their results. Mastering the educational resources depends on the actual level of the student's cognitive and personal development. The diagnostics is presented as a means of control over the training activity and aimed at achieving the following objectives: 1) to identify the "problem areas" in the learning process and personal development; 2) to reveal the successful results with the purpose of establishing positive motivation for the further development; 3 ) to indicate the directions of the internal and external correction; 4) to forecast and plan the next stages of learning and development.

The implementation of the diagnostics objectives is a prerequisite for optimizing the learning process and achieving the required quality of education.

\subsection{Modeling in education}

Modeling as a means of solving the problems of theory and practice is widely applied in pedagogical researches. The models are used either as a research technique for presenting a pedagogical object with the aim of explaining, studying, and clarify; or as an instrument allowing to affect the process of pedagogical object building and functioning based on the analysis of its model representation (ladrovskaya, 2013).

Psycho-pedagogical studies use theoretical models. If mathematical concepts and laws are used for the building models, then the model is called a mathematical one. Applying mathematical methods within the study of the learning process strengthens the requirements for the unambiguity of pedagogical concepts and provides the necessary rigidity to the pedagogical science.

In the educational process, mathematical methods, depending on the purpose of modeling and on the characteristics of the studied area, may be implemented by building a probability, graph, algebraic, or vector model (Kiseleva, Timofeeva, and Bykov, 2013). We consider it necessary to note that "most of the methods currently used for the analysis of humanistic systems, i.e. the systems involving a person, are the modifications of methods, which for a long time have been being created for mechanistic systems" (Bliumin, 2001). However, the results achieved in the natural science and technical fields due to the applications of mathematical methods cannot be considered as a sufficient condition for the successful application of the set of mathematical tools in the pedagogical studies.

The mathematicians A.A Samarskii and A.P. Mikhailov emphasize that the mathematical modeling is fruitful only if the following requirements are met: a clear statement of the basic concepts and assumptions, an a posteriori analysis of the adequacy of the models being used, and assured accuracy of the computational algorithms. Further, the authors note that the modeling of systems involving the "human factor" suggests an accurate delineation of the mathematical and everyday terms as well as careful implementation of the already existing mathematical apparatus within the study of the phenomena and processes (Samarskii and Mikhailov, 2005).

A significant drawback of the mathematical models application in the humanitarian sphere is the difficulty of considering therein the qualitative indicators of the object under study. Among the possible ways to overcome this obstacle, it is possible to specify the use of such relatively new units of mathematics as fuzzy logics and the stochastic analysis as well as integration of the mathematical methods and modern pedagogical methodologies and techniques.

Thus, mathematical modeling, being one of the scientific cognition methods, thereby has the strengths and weaknesses of both theory and experiment. The challenge is to use the universality of the mathematical language to study a pedagogical object minimizing the consequences from the arising "errors" during the transition from the real prototype to its formalized description using mathematical terms. 


\subsection{Vector modeling of pedagogical processes}

The vector method as a means of model building is presented in the work (lasvin, 2001). The scientific analysis of such a complex and multidimensional social reality, as the educational environment, is implemented by the author through the vector model.

The methodology developed by V.A. Iasvin for vector modeling of an educational environment involves building a coordinate system that consists of two axes: the "freedom - dependence" axis, and the "activity - passivity" axis. In order to build within this system of coordinates a vector that corresponds to a particular type of educational environment, it is necessary to answer the diagnostic questions. The answer to each question allows marking one point on the corresponding scale of "activity," "passivity," "freedom," or "dependence." As a result of all the answers in the coordinate system, a corresponding vector is built that allows characterizing this educational environment (lasvin, 2001).

It should be noted that the main purpose of this model is a clear idea of the prevalence of certain indices of the educational environment, in which a child is developing. Using the coordinates on the axes to display the scale of responses to the questions posed in everyday language is a step towards the use of a vector not only as a visual image, but also as a means of transforming the qualitative characteristics into the quantitative indicators.

In their work, N.P. Puchkov and S.I. Tormasin fairly asserted that the methodology for diagnosing the level of formedness of students' competences is different from the traditional knowledge-based approach. "The assessment of competences should take into account their socio-substantive nature reflected in the human activity, which determines the higher requirements to such kind of diagnostics" (Puchkov and Tormasin, 2012). The authors formalize competences in the form of a vector, the components of which are knowledge, skills, abilities, and personal qualities.

Since each component has a number of indicators of its manifestation, competence is set by a matrix composed of the respective row vectors. Various components of competence are unequal. Therefore, the level of importance of each indicator is set by the vector $\overline{\alpha_{1}}=\left(\alpha_{11}, \alpha_{12}, \alpha_{13}\right)$, where $\sum_{j=1}^{3} \alpha_{i j}=1$. Then the scalar product of vectors $\left(\bar{\alpha}_{1}, \bar{b}_{1}\right)=\alpha_{11} \cdot b_{11}+\alpha_{12} \cdot b_{12}+\alpha_{13} \cdot b_{13}$ determines the numerical value expressing the empirical evaluation of the first component $\bar{b}_{1}=\left(b_{11}, b_{12}, b_{13}\right)$ of a competence. The competence assessment is carried out by the two of its quantitative indicators: $\mathrm{P}$ the competence potential, and $\mathrm{R}$ - the quality of its implementation. To assess each indicator, the authors suggest using the scalar product of vectors, and for the study of their stochastic interrelation-the equation of correlation $P=M\left(R_{i}\right)$.

The undeniable value of the approach indicated is that multidimensional vectors provide a really efficient mathematical apparatus for the quantitative assessment of the current status of competence.

However, the effectiveness of the model would not be complete if we do not take into account the dynamic nature of diagnostics during its building. It is necessary to reflect in the model the variability of the object studied and the ability to define the development prospects taking into account the multivariance of movement.

\section{Multidimensional Vectors in Modelling Diagnostic Activity}

\subsection{Principles of the multidimensional diagnostics}

The diagnostics will be taken to mean the controlling and corrective activity aimed at identifying the current state of the object being diagnosed, the degree of its compliance with the parameters specified as well as the determination of the nearest and long-term prospects of its development.

Let us distinguish the conceptual provisions that will serve as a basis for identifying the diagnostic activity principles in the conditions of competence-centered vocational education.

1. The multidimensional nature of competence, which includes the student's knowledge, skills, and personal qualities, makes it necessary to apply the multidimensional diagnostic techniques.

2. The control is not identified with the diagnostics, but represents only one of the diagnostics directions and is intended to obtain data, based on which a pedagogical diagnosis is stated.

3. One of the main diagnostics assignments is to identify the causes of deviations from the set objectives and to determine the ways of their elimination, which contributes to the formation of positive motivation for learning.

4. A major role in the development of a human personality is played by its interaction with the environment. Diagnostics assumes the analysis of not only the progress of the process and its results, but also the conditions, in which it occurs.

5. The educational process is characterized by the constant change in the subject of this process and the 
conditions of its functioning. Diagnostics should be constant, continuous, and promptly take into account all ongoing changes.

6. The judgments on the student's personal qualities on the part of a teacher can be subjective. It is necessary to use a variety of sources for acquisition of the adequate information including the estimates obtained from the competent experts.

7. The competence-centered nature of education contributes to the self-fulfillment and self-development of the student's personality. The diagnostic methods should create conditions for the maximum manifestation of his independence.

8. The student-centered approach suggests the involvement of a student as an active participant in the diagnostic process. Diagnostics should base on the collaborative activity of a teacher and a student.

9. The expretise of a future specialist includes possession of professional competences. The substantial aspect of diagnostics suggests focusing on the profession.

Let us define the diagnostic principles considering the features of the diagnostic activity in the conditions of the competence-centered education.

1. The principle of multidimensionality suggests integration of the cognitive, socio-humanitarian, research, activity-related, and professional components of the competence-centered education (Dorofeev and Piadina, 2014). In order to comply with this principle, it is required to apply means and methods that reflect the multidimensional nature of the object being diagnosed. This requirement can manifest itself from two perspectives. On the one hand, the diagnostics is carried out using a battery of versatile diagnostic tools covering the specified components of competence. On the other hand, the diagnostic tool itself can be multidimensional according to its internal content and purpose. In this case, only one tool is enough for diagnosing competence at a certain stage of its formation.

2. The principle of continuity involves the implementation of diagnostics throughout the whole period of learning a discipline. The personal component of competence can be formed only as a result of continuous learning and development. It is inappropriate to ascertain its maturity only at the final stage, since the end of training no longer provides a possibility to eliminate the defects and fill the gaps in the gained competence. The process of identifying deviations and their reasons with a view to the timely correction should be implemented consistently and systematically.

3. The principle of objectivity provides for the adequacy of judgments rendered with regard to the object being diagnosed and its actual characteristics. The objectivity of the diagnostics is assured with the application of valid qualimetric means and methods. It is necessary to combine optimally the control forms and methods that both use the quantitative scale of assessment and have a qualitative scale for assessment.

4. The principle of anthropocentrism is the embodiment of the student-centered approach in education. It involves the formation of the diagnostic activity based on the constructive interaction of the subjects of the learning process aimed at creating conditions for the most complete fulfillment of the student's personality. In order to meet the requirements of this principle, the student's personality factor should be considered as the basis for the further development as well as for the planning and practical implementation of his advancement along the learning stages.

We accept the principle of multidimensionality as the fundamental principle of diagnostics.

\subsection{Functions of the multidimensional diagnostics}

In accordance with the above-specified understanding of the diagnostics, let us identify the following directions of diagnostic activity:

1) Control-a qualitative and quantitative assessment of the learning outcomes.

2) Correction-elimination of the encountered nonconformities of the obtained estimates provided to the given parameters.

3) Forecasting-correlation of the correction results with the ultimate objective.

The specified directions are interrelated and interdependent. The connecting link is the diagnosing action. The control procedures provide a teacher with the required quantitative and qualitative indicators, based on the analysis of which the pedagogical diagnosis is defined. In its turn, a diagnosis determines the direction and content of the corrective actions, and also is the basis for the forecast rendering. The effectiveness and adequacy of the corrective actions are determined according to the control data. The control is aimed at identifying the degree of compliance of the characteristics of an object being diagnosed with the ultimate outcome indicators, and therefore gives grounds for 
forecasting its further development.

Identification of the functions of any object studied plays an important role in the comprehensive disclosure of its essence. In the conditions of the competence-centered education, the diagnostic activity is enriched with the new content, thus becoming increasingly multifunctional. Table 2 shows the diagnostic activity functions implemented in each of its directions (Latypova and Dorofeev, 2014).

Table 2. The functional model of diagnostics

\begin{tabular}{|l|l|l|l|}
\hline \multirow{2}{*}{ Functions } & \multicolumn{3}{|c|}{ Diagnostics directions } \\
\cline { 2 - 4 } & Control & Correction & Forecasting \\
\hline Cognitive & $\begin{array}{l}\text { Actualizes the existing knowledge and } \\
\text { modes of activity }\end{array}$ & $\begin{array}{l}\text { Promotes the formation of knowledge } \\
\text { and modes of activity }\end{array}$ & $\begin{array}{l}\text { Specifies the objectives set out in the form of } \\
\text { specific tasks }\end{array}$ \\
\hline Socio-humanitarian & $\begin{array}{l}\text { Contributes to identifying the student's } \\
\text { personal attitude to the learning process }\end{array}$ & $\begin{array}{l}\text { Stimulates the development of the } \\
\text { student's personal qualities }\end{array}$ & $\begin{array}{l}\text { Directs the student's identity formation within the } \\
\text { society }\end{array}$ \\
\hline Constructive & Activates the mental activity techniques & $\begin{array}{l}\text { Generates skills and abilities of the } \\
\text { thinking activity }\end{array}$ & $\begin{array}{l}\text { Conditions the development of skills in } \\
\text { transforming the general scientific knowledge } \\
\text { acquired into the professional activity }\end{array}$ \\
\hline Communicative & $\begin{array}{l}\text { Identifies the ability to formulate and } \\
\text { present the material }\end{array}$ & $\begin{array}{l}\text { Activates the ability to line-up } \\
\text { inferences and argue conclusions }\end{array}$ & $\begin{array}{l}\text { Contributes to the implementation of reasonable } \\
\text { judgments in the professional activity }\end{array}$ \\
\hline Orientational & $\begin{array}{l}\text { Determines incompliances with the } \\
\text { parameters specified }\end{array}$ & $\begin{array}{l}\text { Shows the ways to eliminate } \\
\text { inconsistencies }\end{array}$ & $\begin{array}{l}\text { Turns upon obtaining a result significant for the } \\
\text { professional activity }\end{array}$ \\
\hline Mobilization & $\begin{array}{l}\text { Contributes to the awareness of the } \\
\text { learning process as the foundation for } \\
\text { the future professional activity }\end{array}$ & $\begin{array}{l}\text { Organizes intellectual activity as a } \\
\text { student's internal need }\end{array}$ & $\begin{array}{l}\text { Conditions the establishment of the internal } \\
\text { structure of a personality as a specialist }\end{array}$ \\
\hline
\end{tabular}

As the work (Dmoshinskaia, 2004) demonstrates, diagnostics currently is a technology of reflexive interaction between the subjects of the educational process. The technological aspect of the diagnostic activity involves the identification and comprehension of the student's achievements and difficulties in learning disciplines. The diagnostic functions aimed at the development of personal qualities and skills significant for a student as a future specialist come to the foreground.

\subsection{Substantiation of the mathematical model selection for multidimensional diagnostics}

The multidimensional nature of competences, the formation of which appears to be the purpose of learning, imposes restrictions on the traditional organization of the diagnostic activity.

1. The structure of competence includes various components (for example, the actual knowledge, the ability to apply knowledge in the academic and professional activities, as well as the personality traits and target motivation aspects). At the same time, the competence features are determined not only by the composition, but also through the internal interrelations between the components. The change of the components hierarchy under the condition of their fixed composition implies changes in the level of the competence maturity.

2. The competence-building process is expressed through the succession of the current states of a particular system. Each such state is characterized by a specific composition of the component parameters. A change of states is caused by the current and future objectives.

3. During the development of competence, the irreversible qualitative transformations of its components occur. It is essential that the achievement by various subjects of the similar highest points of development is possible against the entirely different initial conditions.

The features specified indicate the inapplicability of the traditional methods of studying and diagnostics built on the isolated measuring of the individual components' indicators to a multidimensional object, such as competence. It is obvious we need to find new approaches that will form the basis of the modeling method adequate to the multidimensional nature of the object under study.

Since the model must reflect the essential features of the study object, the listed characteristics of competence should serve as a basis for the selection of a mathematical apparatus for its diagnostics modeling. The key provisions determining the choice of a model of the multidimensional diagnostics can be rendered through the following statements.

1. The subject of diagnostics should be not only the competence components, but also their interactions. Thus, it is necessary to consider the degree of influence, and the "weight" of each component within the competence structure. 
2. The identification of the level of competence formedness includes not only the assertion of a certain criterion implementation, but also the determination of the functional contribution of each component of competence to the obtained result.

3. It is expedient to study the individual differences in the competence building through the analysis of actual states of the system of components. In turn, to identify the dynamics of the process, there must be a possibility for accumulating the quantitative indicators.

4. Diagnostics is aimed at determining the strategy and tactics of the learning process, i.e. the results of the control activities substantiate the optimal conditions for achieving the ultimate objective.

5. The concretization of training objectives should be carried out at each stage of control and based on the correlation with the final "perfect" state as well as take into account all the parameters of the system at the present stage.

6. In order to build a scale of assessments, it is expedient to apply a criterion-regulatory approach since it is the most consistent with the objectives of the student-centered diagnostics.

The use of the apparatus of multidimensional vectors appears to be an adequate means of implementation of the specified set of requirements when building a diagnostic model. Indeed, vector modeling in the best possible way allows considering the multidimensionality of competence and the dynamism of the process of its building. Operations with vectors assist in obtaining a quantitative assessment not only of the current state, but also of the prospects of the change understood as a transition to the next state.

\subsection{Multidimensional vectors in modeling the diagnostics of competences}

The development of the idea of vector interpretation is carried out in the direction of using the vector characteristics and mathematical operations on vectors to reflect the dynamics of the competence formation process.

If the state of any object of the system is defined by the $n$ data, then this state can be presented as a point of a certain $n$-dimensional space. Such representation allows us to apply the known geometric methods for the study of the objects considered. The multidimensional space is an abstract concept that is intended to describe in the language of geometry the objects and phenomena, which do not accept images in the conventional sense.

The objects of the multidimensional space are the multicomponent vectors that represent the ordered sets of figures (coordinates or components). Within the context of development of the diagnostics vector model, the vector coordinates are the quantitative indicators of the student's studied characteristics that correspond to the competence components.

Let us designate $p_{i j}$ as the indicators of formedness of the competence components, wherein $i=1, \ldots, n$, $j=0, \ldots, k$, where $n$ is the number of components, $k$ is the number of control procedures. It is obvious that the number $n$ is determined through the competence structure, the degree of its particularization, and probably through any finite number in general. The number $k$ can be specified on the assumption of the selected approach to determining the frequency of the control procedures performance. The choice can be substantiated either by the time intervals of the

learning process or by the structural units of the educational material. The $p_{i j}$ values can be absolute of relative (corrected). In the latter case, these are figures from 0 to 1, which are the results of dividing the absolute value obtained at the current stage by the limit "ideal" value of this component. In order to take into account the varying degree of influence of the competence elements, let us introduce the weighting factors $\lambda_{i}\left(0<\lambda_{i} \leq 1\right)$ for each component.

Following the results of the input control, the vector $\bar{p}_{i 0}=\left(p_{10}, p_{20}, \ldots, p_{n 0}\right)$ is determined, which describes the initial (zero) actual state of competence. After the first control, the first measurement of the components' indicators, we obtain vector $\bar{p}_{i 1}=\left(p_{11}, p_{21}, \ldots, p_{n 1}\right)$. This vector characterizes the first actual state. When calculating by the appropriate formula the modulus of vector $\bar{a}_{i 1}$, which is the difference of vectors $\bar{p}_{i 1}$ and $\bar{p}_{i 0}$, we can determine the competence advancement degree as a point in the $n$-dimensional space.

However, the length of the vector does not provide all the necessary information. Therefore, it is expedient to calculate the angle between vectors $\bar{a}_{i 1}$ and $\bar{S}$. Vector $\bar{S}$ connects the initial and final states. The final state is taken to mean the target state of an object.

According to the results of the subsequent measurements, we determine the vectors $\bar{p}_{i 2}=\left(p_{12}, p_{22}, \ldots, p_{n 2}\right)$, $\bar{p}_{i 3}=\left(p_{13}, p_{23}, \ldots, p_{n 3}\right)$ and so on up to $\bar{p}_{i k}=\left(p_{1 k}, p_{2 k}, \ldots, p_{n k}\right)$. The components of these vectors are the quantitative 
indicators of the level of the student's competence maturity at each stage of control.

Let us make vector $\bar{p}_{1 j}=\left(p_{11}, p_{12}, p_{13}, \ldots, p_{1 k}\right)$ from the first coordinates of the obtained vectors. It provides a clear idea of the dynamics of formation of the competence's first component. The study of such a vector will allow revealing the impact of the methodological tools and techniques on the process of formation of this component. It is possible to obtain profiles of each component and make the necessary conclusions by their aggregate.

\subsection{Modeling an individual educational path}

The multidimensional diagnostics serves as the technological ground for the formation of an individual educational path. Within the framework of the mathematical model of diagnostics based on multidimensional vectors, it is possible to specify the actual states (initial, current, and final) as the educational path components.

The development of a student in the course of learning an academic discipline can be considered as the transformation of the qualitative characteristics of his personality as well as the emergence of a new qualitative state revealing the potential opportunities. Thus, it is the movement from one qualitative state to another. The measure of movement is the path, and vectors are the most convenient way to describe the path mathematically. Therefore, it seems natural to describe the process of an individual path designing in terms of a vector model.

Let us consider the vector interpretation of the main directions of the diagnostic activity. The results of the input control using the appropriate techniques are reduced to a single system of measures, and form the vector of initial state $\bar{p}_{i 0}=\left(p_{10}, p_{20}, \ldots, p_{n 0}\right)$, wherein each coordinate is a quantitative indicator of a certain component of the competence.

The obtained coordinates are compared with the "reference" indicators, being the quantitative expression of the requirements to the compulsory minimum of knowledge and skills necessary for learning the given academic discipline. A quantitative analysis of the obtained deviations followed by their qualitative comprehension gives grounds for a pedagogical diagnosis.

In turn, the diagnosis allows determining the prospect of the system's further advancement to the ultimate outcome through the building vector $\bar{S}$ that connects the existing initial and the ideal final states.

Vector $\bar{S}$ determines the direction of the path of learning an academic discipline, i.e. the process of acquiring concepts and properties, laws and techniques using didactic forms and means, which is the content of the learning process. The methods and means of learning are aimed at ensuring the pedagogical conditions for the best possible way of mastering the relevant competence by the given student. The efficiency of these conditions is detected during the process of the current control.

At each stage, the results of the current control are formalized in the form of vectors $\bar{p}_{i 1}=\left(p_{11}, p_{21}, \ldots, p_{n 1}\right)$, $\bar{p}_{i 2}=\left(p_{12}, p_{22}, \ldots, p_{n 2}\right)$, etc. Each of these vectors represents the competence "profile" at the given moment of the learning process, i.e. provides an idea of the current state of the system. In order to determine the dynamics of movement, its velocity and direction, it is necessary to consider not vectors $\bar{p}_{i 1}, \bar{p}_{i 2}, \bar{p}_{i 3}, \ldots, \bar{p}_{i k}$ themselves, but the differences between the previous and the subsequent ones in each pair of the adjacent vectors. Such vectors-differences (i.e. their lengths and deviations from vector $\bar{S}$ ) provide the data, based on which the diagnosis can be stated, the content of which comprises the analysis of the identified shortcomings and achievements. The diagnostic conclusion is used to select the forms and means of correction and forecasting of the next state of the system.

The degree of the corrective actions successfulness is revealed as an outcome of the implementation of the controlling procedures and results in transition to the next actual state, for which the same formalization procedures are carried out in the language of vectors that enable the diagnosis and determination of the further movement direction. The vectors, the coordinates of which quantitatively express both the knowledge- and personality-based components of competence, provide for the continuous refinement of the individual path.

The purpose of the final control is the correlation of the obtained learning outcome with the learning objective. The ideal vector $\bar{S}$ is compared with the real vector, which is equal to the difference of vectors $\bar{p}_{i k}$ and $\bar{p}_{i 0}$, characterizing the degrees of the competence acquirement. The comparison is carried out according to such vector characteristics as length and direction. The difference of moduli (lengths) of vectors and the angle between them are calculated. Such numerical indicators are necessary for the diagnosis aimed at the forecasting of competences development in the future professional activity. Herein, it is important to conduct the reflexion based on the mathematical methods over the arrays of figures-the coordinates of vectors that characterize the actual states.

Thus, the designing of an individual path based on the vector model of multidimensional diagnostics allows: 
1) to formalize the stages of the competence formation process with the purpose of the further mathematical processing of the diagnostic procedures' results;

2) to provide for the quantitative assessment of the dissimilar component parts of multidimensional competence.

3) to reflect the dynamics of passing the path.

\section{Discussion of the Results}

The above-mentioned mathematical model of multidimensional diagnostics features the following essential properties:

1. Representing competence as a multicomponent vector reflects its multidimensionality. Using the weighting factors allows ranking the competence components and identifying their interrelation.

2. Through mathematical operations, we can determine the role of each competence component in the results achievement.

3. The presentation of an actual state in the form of an ordered set of figures allows performing its quantitative analysis, based on which a qualitative characteristic of the object under study can be obtained.

4. The a posteriori numerical assessments of the actual state set the direction and pace of advancement through the indication of the next actual state that brings the object closer to the target.

5. A coordinatewise analysis of the multidimensional vector allows taking timely corrective measures.

Thus, modeling diagnostics using multidimensional vectors provides a certain degree of demonstrativeness, while ensuring efficient application of the mathematical apparatus, and reflects the dynamics of the competence-building process. In terms of the proposed model, this process is presented as the movement from one point of the multidimensional space to another. Therefore, it is logical to interpret the planning and implementation of the competence formation as the path designing.

\section{Conclusion}

The change in the approach to the learning objective articulation actualizes the problem of searching for new methods and means of identifying the level of compliance with the applicable criteria. The multidimensionality of the education outcome on the one hand, and the recognition of the priority of the personality development during the learning process on the other hand, necessitate the implementation of the pedagogical diagnostics based on the principles of multidimensionality, continuality, anthropocentrism, and objectivity.

The diagnostic functions implemented in each of its directions (control, correction, and forecasting) allow optimizing the learning process through designing an individual educational path. The vector method is an effective means of formalizing the planning and implementation of the student's advancement along the individual path. The modeling based on multicomponent vectors allows implementing the specified diagnostic principles, while meeting the requirements to the models. The optimal combination of mathematical techniques with the traditional didactic means creates conditions for achieving the objectives of the modern education.

The purpose of the individual path designing is to make the process of the academic discipline learning as efficient as possible. The efficiency of the process involves obtaining the best result under these conditions. However, this result must be achieved due to the best (i.e. optimal) arrangement of the activity. The considered interpretation of the learning process leads to the articulation of the new term-"optimal individual path"-the pure definition of which is possible only in the condition of defining the criterion of optimality. Further research may be aimed at identifying the criteria characterizing the optimality of an individual educational path.

\section{Acknowledgements}

This research project was supported by the project B15-64 "Vector modelling of pedagogical processes" of the Sterlitamak Branch of the Bashkir State University.

\section{References}

Almazova, O.V. (2007). Psikhologo-pedagogicheskaia diagnostika: ucheb. posobie [Psychological and pedagogical diagnostics: Study guide]. Ekaterinburg: Kalinina, G.P. [in Russian].

Anan'ev, B.G. (1968). Chelovek kak predmet poznaniia [A Person as an object of knowledge]. Leningrad: Leningrad University [in Russian]. 
Bogataia, L.N. (2012). Filosofiia mnogomernogo cheloveka [Philosophy of a Multidimensional Person]. Mnogomernost' i tselostnost' cheloveka v filosofii, nauke i religii: materialy Mezhdunar. nauchno-obrazovatel'noi konferentsii - Multidimensionality and Integrity of a Person in Philosophy, Science, and Religion: Proceedings of the International Scientific and Educational Conference (pp. 219-226). Kazan: Kazan University [in Russian]..

Dmoshinskaia, N.G. (2004). Diagnostika osvoeniia studentami pedagogicheskikh distsiplin [Diagnostics of the Development of Pedagogical Disciplines by Students]. Extended abstract of Candidate's thesis. Saint Petersburg [in Russian].

Dorofeev, A.V., \& Latypova, A.F. (2015). Printsip mnogomernosti v kompetentnostnom obrazovanii [The Principle of Multidimensionality within the Competence-based Education]. Sbornik nauchnykh trudov Sworld - Collection of Scientific Papers Sworld, Vol. 8, 1(38), 83-86 [in Russian].

Dorofeev, A.V.\& Piadina, J.V. (2014). Design of Multidimensional Mathematical Training. European Journal of Natural History, 3, 13-15.

ladrovskaya, M.V. (2013). Modeli v pedagogike [Models in Pedagogics]. Vestnik Tomskogo gosudarstvennogo universiteta - Bulletin of the Tomsk State University, 366, 139-143 [in Russian].

lakushevich, V.I., \& Burmakina, N.A. (2013). Komp'iuternaia pedagogicheskaia diagnostika: monografiia [Computer pedagogical diagnostics: Monograph]. Krasnoyarsk: Krasnoyarsk State Pedagogical University named after V.P. Astafyev [in Russian].

Ialalov, F.G. (2012). Mnogomernye pedagogicheskie kompetentsii [Multidimensional pedagogical competences]. Pedagogika Pedagogics, 4, 45-53 [in Russian].

Ialalov, F.G. (2013). Professional'naia mnogomernost': monografiia [Professional multidimensionality: monograph]. Kazan: Tsentr innovatsionnykh tekhnologii [in Russian].

Iasvin, V.A. (2001). Obrazovatel'naia sreda: ot modelirovaniia k proektirovaniiu [Educational environment: from modeling to designing]. Moscow: Smysl [in Russian].

Ingenkamp, K. (1991). Pedagogicheskaia diagnostika [Pedagogical Diagnostics]. Moscow: Pedagogika [in Russian].

Kiseleva, O.M., Timofeeva, N.M., \& Bykov, A.A. (2013). Formalizatsiia elementov obrazovatel'nogo protsessa na osnove matematicheskikh metodov [Formalization of the elements of educational process based on mathematical methods]. Sovremennye problemy nauki i obrazovaniia - Contemporary Problems of Science and Education, 1. Retrieved from http://science-education.ru/107-8283 [in Russian].

Latypova, A.F., \& Dorofeev, A.V. (2014). Funktsional'naia model' mnogomernoi diagnostiki rezul'tatov professional'nogo obrazovaniia [The functional model of a multidimensional diagnostics of the vocational education results]. Problemy sotsial'noekonomicheskogo razvitiia Sibiri: Nauchnyi zhurnal Bratskogo gosudarstvennogo universiteta - Problems of the Social and Economic Development of Siberia: Scientific Journal of the Bratsk State University, 4, 113-116 [in Russian].

Mikhailychev, E.A. (2004). K poniatiinomu apparatu pedagogicheskoi diagnostiki [To the conceptual apparatus of pedagogical diagnostics]. Pedagogicheskaia diagnostika - Pedagogical Diagnostics, 2, 33-49 [in Russian].

Morgun, V.F. (1992). Kontseptsiia mnogomernogo razvitiia lichnosti i ee prilozheniia [The concept of the multidimensional development of a personality and its application]. Filosofskaia i sotsiologicheskaia mysl' - Philosophical and Sociological Thought, 2, 27-40 [in Russian].

Nurullin, R.A. (2013). Philosophic Problems of Correlation between Professional Education and Education in General. Middle-East Journal of Scientific Research, 17(2), 226-232.

Puchkov, N.P., \& Tormasin, S.I. (2012). Metodicheskie aspekty formirovaniia, integrirovaniia i otsenki kompetentsii: Metod. rekomendatsii [Methodical aspects of the formation, integration, and assessment of the competences: Methodological Recommendations]. Tambov: FSBEI HPO "TSTU" [in Russian].

Sabirov, A.G. (2012). Mnogomernost' cheloveka v sovremennoi filosofskoi antropologii [The Multidimensionality of a person within the modern philosophical anthropology]. Mnogomernost' i tselostnost' cheloveka v filosofii, nauke i religii: Materialy Mezhdunar. nauchno-obrazovatel'noi konf - Multidimensionality and Integrity of a Person in Philosophy, Science, and Religion: Proceedings of the International Scientific and Educational Conference (pp. 294-297). Kazan: Kazan University [in Russian].

Samarskii, A.A., \& Mikhailov, A.P. (2005). Matematicheskoe modelirovanie: Idei. Metody. Primery [Mathematical Modeling: Ideas. Methods. Examples]. Moscow: FIZMATLIT [in Russian].

Stejnberg, V.E. (2001). Mnogomernost' kak didakticheskaia kategoriia [Multidimensionality as a didactic category]. Obrazovanie i nauka - Education and Science, 10, 20-30 [in Russian].

Stejnberg, V.E. (2002). Mnogomernye didakticheskie instrumenty: teoriia, metodika, praktika [Multidimensional Didactic Tools: Theory, Methodology, Practice]. Moscow: Narodnoe obrazovanie. Shkol'nye tekhnologii [in Russian].

Ushakov, A.A. (2010). Diagnostika kachestva fiziko-matematicheskoi podgotovki studentov v tekhnicheskom vuze na osnove testovykh tekhnologii [Diagnostics of the quality of physical and mathematical training of students in a technical educational institution on the basis of testing technologies]. Extended abstract of Candidate's thesis. Kazan [in Russian]. 